\title{
Fixed Points and Common Fixed Points of Quasi-Contractive Mappings on Partially Ordered-Cone Metric Spaces
}

\author{
Hailan Jin, Yongjie Piao \\ Department of Mathematics, College of Science, Yanbian University, Yanji, China \\ Email: hljin98@ybu.edu.cn, sxpyi@ybu.edu.cn \\ Received 7 October 2014; revised 28 October 2014; accepted 10 November 2014 \\ Copyright $@ 2014$ by authors and Scientific Research Publishing Inc. \\ This work is licensed under the Creative Commons Attribution International License (CC BY). \\ http://creativecommons.org/licenses/by/4.0/

(c) (i) Open Access

\begin{abstract}
In this paper, we use the mappings with quasi-contractive conditions, defined on a partially ordered set with cone metric structure, to construct convergent sequences and prove that the limits of the constructed sequences are the unique (common) fixed point of the mappings, and give their corollaries. The obtained results improve and generalize the corresponding conclusions in references.
\end{abstract}

\section{Keywords}

\section{Common Fixed Point, Cone Metric Space, Complete}

\section{Introduction}

Huang and Zhang [1] recently have introduced the concept of cone metric spaces and have established fixed point theorems for a contractive type map in a normal cone metric space. Subsequently, some authors [2]-[7] have generalized the results in [1] and have studied the existence of common fixed points of a finite self maps satisfying a contractive condition in the framework of normal or non-normal cone metric spaces. On the other hand, some authors discussed (common) fixed point problems for contractive maps defined on a partially ordered set with cone metric structure [8]-[13]. These results improved and generalized many corresponding (common) fixed point theorems of contractive maps on cone metric spaces. Here, we will obtain (common) fixed point theorems of maps with certain quasi-contractive conditions on a partially ordered set with cone metric structure.

Let $E$ be a real Banach space. A subset $P_{0}$ of $E$ is called a cone if and only if:

i) $P_{0}$ is closed, nonempty, and $P_{0} \neq\{0\}$; 
ii) $a, b \in \mathbb{R}, a, b \geq 0$ and $x, y \in P_{0}$ implies $a x+b y \in P_{0}$;

iii) $P_{0} \cap\left(-P_{0}\right)=\{0\}$.

Given a cone $P_{0} \subset E$, we define a partial ordering $\leq$ on $E$ with respect to $P_{0}$ by $x \leq y$ if and only if $y-x \in P_{0}$. We will write $x<y$ to indicate that $x \leq y$ but $x \neq y$, while $x \ll y$ will stand for $y-x \in \operatorname{int} P_{0}$ (interior of $P_{0}$ ).

The cone $P_{0}$ is called normal if there is a number $K>0$ such that for all $x, y \in E$,

$$
0 \leq x \leq y \Rightarrow\|x\| \leq K\|y\| \text {. }
$$

The least positive number $K$ satisfying the above is called the normal constant of $P_{0}$. It is clear that $K \geq 1$.

In the following we always suppose that $E$ is a real Banach space, $P_{0}$ is a cone in $E$ with int $P_{0} \neq \varnothing$ and $\leq$ is a partial ordering with respect to $P_{0}$.

Let $X$ be a nonempty set. Suppose that the mapping $d: X \times X \rightarrow E$ satisfies

d1) $0 \leq d(x, y)$ for all $x, y \in X$ and $d(x, y)=0$ if and only if $x=y$;

d2) $d(x, y)=d(y, x)$ for all $x, y \in X$;

d3) $d(x, y) \leq d(x, z)+d(z, y)$, for all $x, z, y \in X$.

Then $d$ is called a cone metric on $X$, and $(X, d)$ is called a cone metric space.

Let $(X, d)$ be a cone metric space. We say that a sequence $\left\{x_{n}\right\}$ in $X$ is

e) Cauchy sequence if for every $c \in E$ with $0 \ll c$, there is an $N$ such that for all $n, m>N, d\left(x_{m}, x_{n}\right) \ll c$;

g) convergent sequence if for every $c \in E$ with $0 \ll c$, there is an $N$ such that for all $n>N$ such that $d\left(x_{n}, x\right) \ll c$ for some $x \in E$. Let $x_{n} \rightarrow x$ or $\lim _{n \rightarrow \infty} x_{n}=x$.

$(X, d)$ is said to be complete if every Cauchy sequence in $X$ is convergent in $X$.

Let $(X, d)$ be a cone metric space, $f: X \rightarrow X$ and $x_{0} \in X$. $f$ is said to be continuous [13] at $x_{0}$ if for any sequence $x_{n} \rightarrow x_{0}$, we have $f x_{n} \rightarrow f x_{0}$.

Lemma 1 [14] Let $(X, d)$ be a cone metric space. Then the following properties hold:

1) if $u \leq v$ and $v \ll w$, then $u \ll w$; if $0 \leq a \ll c$ for all $c \in \operatorname{int} P_{0}$, then $a=0$;

2) if $a \leq \lambda a$ where $a \in P_{0}$ and $0<\lambda<1$, then $a=0$.

Lemma 2 [15] Let $(X, d)$ be a cone metric space, $\left\{x_{n}\right\}$ a sequence in $X$ and $\left\{a_{n}\right\}$ a sequence in $P_{0}$ and $a_{n} \rightarrow 0$. If $d\left(x_{n}, x_{m}\right) \leq a_{n}$ for any $m>n>1$, then $\left\{x_{n}\right\}$ is Cauchy.

\section{Main Results}

At first, we give an example to show that there exists a self-map $f$ on a partially ordered set $(X, \sqsubseteq)$ such that for each $x \in X$ there exists $y$ satisfying $x=f y$ and $x \sqsubseteq y$.

Example Let $X=R$ be a real space. Define $f: X \rightarrow X$ by

$$
f(x)= \begin{cases}\frac{x}{2}, & \text { for } x \leq 1 \\ 1-\frac{x}{2}, & \text { for } 1<x \leq 2 \\ 3 x-6, & \text { for } 2<x \leq 3 \\ \frac{x}{3}+2, & \text { for } x>3\end{cases}
$$

Then obviously, for each $x \in X$, there exists $y \in X$ satisfying $x=f y$ and $x \sqsubseteq y$.

$(X, \sqsubseteq, d)$ is said to be a partially order-cone metric space if $(X, \sqsubseteq)$ is a partially ordered set and $(X, d)$ is a cone metric space.

Theorem 1 Let $(X, \sqsubseteq, d)$ be a complete partially ordered-cone metric space. Suppose that a map $f: X \rightarrow X$ is continuous and the following two assertions hold:

i) there exist $A, B, C, D, E \geq 0$ with $A+B+C+2 E<1$ and for $x, y \in X$ with $x \sqsubseteq y$, such that

$$
d(x, y) \leq A d(f x, f y)+B d(x, f x)+C d(y, f y)+D d(x, f y)+E d(f x, y) ;
$$

ii) for each $x \in X$, there exists $y \in X$ such that $x=f y$ and $x \sqsubseteq y$.

Then $f$ has a fixed point $x^{*} \in X$. Furthermore, if any two elements $x$ and $y$ in Fix $(f)$ are comparative and 
$A+D+E<1$, then $f$ has a unique fixed point in $X$.

Proof Take any $x_{0} \in X$, then by ii), we obtain a sequence $\left\{x_{n}\right\}$ as follows: $x_{n-1}=f x_{n}$ for all $n \in \mathbb{N}$ and $x_{0} \sqsubseteq x_{1} \sqsubseteq x_{2} \sqsubseteq \cdots \sqsubseteq x_{n} \sqsubseteq \cdots$.

For any fixed $n \in \mathbb{N}$, since $x_{n} \sqsubseteq x_{n+1}$, by i),

$$
\begin{aligned}
d\left(x_{n}, x_{n+1}\right) & \leq \operatorname{Ad}\left(f x_{n}, f x_{n+1}\right)+B d\left(x_{n}, f x_{n}\right)+C d\left(x_{n+1}, f x_{n+1}\right)+D d\left(x_{n}, f x_{n+1}\right)+E d\left(f x_{n}, x_{n+1}\right) \\
& =\operatorname{Ad}\left(x_{n-1}, x_{n}\right)+B d\left(x_{n}, x_{n-1}\right)+C d\left(x_{n+1}, x_{n}\right)+E d\left(x_{n-1}, x_{n+1}\right) \\
& \leq \operatorname{Ad}\left(x_{n-1}, x_{n}\right)+B d\left(x_{n}, x_{n-1}\right)+C d\left(x_{n+1}, x_{n}\right)+E\left[d\left(x_{n-1}, x_{n}\right)+d\left(x_{n}, x_{n+1}\right)\right],
\end{aligned}
$$

so $d\left(x_{n}, x_{n+1}\right) \leq\left(\frac{A+B+E}{1-C-E}\right) d\left(x_{n-1}, x_{n}\right), \quad \forall n \in \mathbb{N}$.

Let $k:=\frac{A+B+E}{1-C-E}$, then $0 \leq k<1$ by i) and

$$
d\left(x_{n}, x_{n+1}\right) \leq k d\left(x_{n-1}, x_{n}\right), \quad \forall n \in \mathbb{N} .
$$

Repeating this process,

$$
d\left(x_{n}, x_{n+1}\right) \leq k^{n} d\left(x_{0}, x_{1}\right), \quad \forall n \in \mathbb{N} .
$$

Let $m>n \geq 1$, then from the above,

$$
d\left(x_{n}, x_{m}\right) \leq \sum_{i=n}^{m-1} d\left(x_{i}, x_{i+1}\right) \leq \sum_{i=n}^{m-1} k^{i} d\left(x_{0}, x_{1}\right) \leq\left(\frac{k^{n}}{1-k}\right) d\left(x_{0}, x_{1}\right):=a_{n} .
$$

Obviously, $a_{n} \in P_{0}$ and $a_{n} \rightarrow 0$ as $n \rightarrow \infty$ since $0 \leq k<1$ So $d\left(x_{n}, x_{m}\right) \leq a_{n}$ for all $m>n \geq 1$, hence $\left\{x_{n}\right\}_{n=1}^{\infty}$ is a Cauchy sequence by Lemma 2 and there exists $x^{*} \in X$ such that $x_{n} \rightarrow x^{*}$ by the completeness of $X$. Since $f$ is continuous and $x_{n}=f x_{n+1}$, so $x^{*}=f x^{*}$, i.e., $x^{*}$ is a fixed point of $f$.

If $x^{*}$ and $y^{*}$ are all fixed points of $f$ and suppose that $x^{*} \sqsubseteq y^{*}$, then by i),

$$
\begin{aligned}
d\left(x^{*}, y^{*}\right) & \leq A d\left(f x^{*}, f y^{*}\right)+B d\left(x^{*}, f x^{*}\right)+C d\left(y^{*}, f y^{*}\right)+D d\left(x^{*}, f y^{*}\right)+E d\left(f x^{*}, y^{*}\right) \\
& \leq(A+D+E) d\left(x^{*}, y^{*}\right) .
\end{aligned}
$$

Hence $x^{*}=y^{*}$ by (2) in Lemma 1 , so $x^{*}$ is the unique fixed point of $f$.

Another version of Theorem 1 is following:

Theorem 2 Let $(X, \sqsubseteq, d)$ be a complete partially ordered-cone metric space. Suppose that $f: X \rightarrow X$ is continuous and the following two assertions hold:

i) there exist $\alpha, \beta, \gamma \geq 0$ with $\alpha+2 \beta+2 \gamma<1$ and for all $x, y \in X$ with $x \sqsubseteq y$,

$$
d(x, y) \leq \alpha d(f x, f y)+\beta[d(x, f x)+d(y, f y)]+\gamma[d(x, f y)+d(f x, y)] ;
$$

ii) for each $x \in X$, there exists $y \in X$ such that $x=f y$ and $x \sqsubseteq y$.

Then $f$ has a fixed point $x^{*} \in X$. Furthermore, if $x$ and $y$ is comparative for all $x, y \in \operatorname{Fix}(f)$, then $f$ has an unique fixed point in $X$.

Proof Take $A=\alpha, B=C=\beta$ and $D=E=\gamma$, then the conclusion is true by Theorem 1 .

From now, we give common fixed point theorems for a pare of maps.

Theorem 3 Let $(X, \sqsubseteq, d)$ be a complete partially ordered-cone metric space. If $f, g: X \rightarrow X$ are two maps such that $f$ or $g$ is continuous and the following two assertions hold:

i) there exist $A, B, C, D, E \geq 0$ with $B+D<1, C+E<1$ and $\frac{A+B+E}{1-C-E} \frac{A+C+D}{1-B-D}<1$ such that for all comparative $x, y \in X d(x, y) \leq A d(f x, g y)+B d(x, f x)+C d(y, g y)+D d(x, g y)+E d(f x, y)$;

ii) for each $x \in X$, there exist $y_{1}, y_{2} \in X$ such that $x=f y_{1}, x=g y_{2}$ and $x \sqsubseteq y_{1}, x \sqsubseteq y_{2}$.

Then $f$ and $g$ have a common fixed point $x^{*} \in X$. Furthermore, if $x$ and $y$ in $\operatorname{Fix}(f) \cap$ Fix $(g)$ are compara- 
tive and $A+D+E<1$, then $\operatorname{Fix}(f) \cap \operatorname{Fix}(g)$ is singleton.

Proof Take any element $x_{0} \in X$, then using ii), we can construct a sequence $\left\{x_{n}\right\}$ satisfying the following condition $x_{2 n}=f x_{2 n+1}, x_{2 n+1}=g x_{2 n+2}$ for all $n=0,1, \cdots$, and $x_{0} \sqsubseteq x_{1} \sqsubseteq x_{2} \sqsubseteq \cdots \sqsubseteq x_{n} \sqsubseteq \cdots$.

For any $n \in \mathbb{N}$, by i), we have

$$
\begin{aligned}
d\left(x_{2 n+1}, x_{2 n+2}\right) \leq & A d\left(f x_{2 n+1}, g x_{2 n+2}\right)+B d\left(x_{2 n+1}, f x_{2 n+1}\right)+C d\left(x_{2 n+2}, g x_{2 n+2}\right) \\
& +D d\left(x_{2 n+1}, g x_{2 n+2}\right)+E d\left(f x_{2 n+1}, x_{2 n+2}\right) \\
= & A d\left(x_{2 n}, x_{2 n+1}\right)+B d\left(x_{2 n+1}, x_{2 n}\right)+C d\left(x_{2 n+2}, x_{2 n+1}\right)+E d\left(x_{2 n}, x_{2 n+2}\right) \\
\leq & (A+B+E) d\left(x_{2 n}, x_{2 n+1}\right)+(C+E) d\left(x_{2 n+1}, x_{2 n+2}\right),
\end{aligned}
$$

hence

$$
d\left(x_{2 n+1}, x_{2 n+2}\right) \leq K_{1} d\left(x_{2 n}, x_{2 n+1}\right), \quad \forall n \in \mathbb{N}
$$

where $K_{1}=\frac{A+B+E}{1-C-E}$. And

$$
\begin{aligned}
d\left(x_{2 n+3}, x_{2 n+2}\right) \leq & A d\left(f x_{2 n+3}, g x_{2 n+2}\right)+B d\left(x_{2 n+3}, f x_{2 n+3}\right)+C d\left(x_{2 n+2}, g x_{2 n+2}\right) \\
& +D d\left(x_{2 n+3}, g x_{2 n+2}\right)+E d\left(f x_{2 n+3}, x_{2 n+2}\right)+A d\left(x_{2 n+2}, x_{2 n+1}\right) \\
& +B d\left(x_{2 n+3}, x_{2 n+2}\right)+C d\left(x_{2 n+2}, x_{2 n+1}\right)+D d\left(x_{2 n+3}, x_{2 n+1}\right) \\
\leq & (A+C+D) d\left(x_{2 n+2}, x_{2 n+1}\right)+(B+D) d\left(x_{2 n+3}, x_{2 n+2}\right),
\end{aligned}
$$

hence

$$
d\left(x_{2 n+3}, x_{2 n+2}\right) \leq K_{2} d\left(x_{2 n+2}, x_{2 n+1}\right), \quad \forall n \in \mathbb{N}
$$

where $K_{2}=\frac{A+C+D}{1-B-D}$.

Let $K=K_{1} K_{2}$, then $0<K<1$ by i), and by induction, for any $n=0,1,2, \cdots$

$$
\begin{aligned}
d\left(x_{2 n+1}, x_{2 n+2}\right) & \leq K_{1} d\left(x_{2 n}, x_{2 n+1}\right) \leq K_{1} K_{2} d\left(x_{2 n-1}, x_{2 n}\right)=K d\left(x_{2 n-1}, x_{2 n}\right) \\
& \leq \cdots \leq K^{n} d\left(x_{1}, x_{2}\right) K_{1} K^{n} d\left(x_{0}, x_{1}\right) \\
d\left(x_{2 n+2}, x_{2 n+3}\right) & \leq K_{2} d\left(x_{2 n+1}, x_{2 n+2}\right) \leq K_{1}\left[K_{1} K^{n} d\left(x_{0}, x_{1}\right)\right]=K^{n+1} d\left(x_{0}, x_{1}\right) .
\end{aligned}
$$

For any $p, q \in \mathbb{N}$ with $p<q$,

$$
\begin{aligned}
d\left(x_{2 p+1}, x_{2 q+1}\right) & \leq \sum_{i=2 p+1}^{2 q} d\left(x_{i}, x_{i+1}\right) \leq\left(K_{1} \sum_{i=p}^{q-1} K^{i}+\sum_{i=p+1}^{q} K^{i}\right) d\left(x_{0}, x_{1}\right) \leq \frac{K^{p}\left(K_{1}+K\right)}{1-K} d\left(x_{0}, x_{1}\right) \\
& \leq \frac{K^{p}\left(K_{1}+1\right)}{1-K} d\left(x_{0}, x_{1}\right) \leq M K^{p} d\left(x_{0}, x_{1}\right),
\end{aligned}
$$

where $M=\frac{2}{1-k} \max \left\{K_{1}, 1\right\}$. Similarly,

$$
\begin{aligned}
d\left(x_{2 p}, x_{2 q+1}\right) & \leq \sum_{i=2 p}^{2 q} d\left(x_{i}, x_{i+1}\right) \leq\left(\sum_{i=p}^{q} K^{i}+K_{1} \sum_{i=p}^{q-1} K^{i}\right) d\left(x_{0}, x_{1}\right) \\
& \leq \frac{K^{p}\left(1+K_{1}\right)}{1-K} d\left(x_{0}, x_{1}\right) \leq M K^{p} d\left(x_{0}, x_{1}\right) \\
d\left(x_{2 p}, x_{2 q}\right) & \leq \sum_{i=2 p}^{2 q-1} d\left(x_{i}, x_{i+1}\right) \leq\left(\sum_{i=p}^{q-1} K^{i}+K_{1} \sum_{i=p}^{q-1} K^{i}\right) d\left(x_{0}, x_{1}\right) \\
& \leq \frac{K^{p}\left(1+K_{1}\right)}{1-K} d\left(x_{0}, x_{1}\right) \leq M K^{p} d\left(x_{0}, x_{1}\right)
\end{aligned}
$$




$$
\begin{aligned}
d\left(x_{2 p+1}, x_{2 q}\right) & \leq \sum_{i=2 p+1}^{2 q-1} d\left(x_{i}, x_{i+1}\right) \leq\left(K_{1} \sum_{i=p}^{q-1} K^{i}+\sum_{i=p+1}^{q-1} K^{i}\right) d\left(x_{0}, x_{1}\right) \\
& \leq \frac{K^{p}\left(K_{1}+K\right)}{1-K} d\left(x_{0}, x_{1}\right) \leq M K^{p} d\left(x_{0}, x_{1}\right) .
\end{aligned}
$$

So for any $m, n \in \mathbb{N}$ with $m>n>0$, there exists $\alpha(n) \in \mathbb{N}$ with $\frac{n-1}{2} \leq \alpha(n) \leq \frac{n}{2}$, that is, $\alpha(n)=\left[\frac{n}{2}\right]$ such that

$$
d\left(x_{m}, x_{n}\right) \leq M K^{\alpha(n)} d\left(x_{0}, x_{1}\right):=a_{n} .
$$

Obviously, $a_{n} \in P_{0}$ and $a_{n} \rightarrow 0$ as $n \rightarrow \infty$ since $K<1$. So $d\left(x_{m}, x_{n}\right) \leq a_{n}$ for all $m>n \geq 1$, hence $\left\{x_{n}\right\}$ is Cauchy by Lemma 2 and there exists $x^{*} \in X$ such that $x_{n} \rightarrow x^{*}$.

Suppose that $f$ is continuous, then $x^{*}=f x^{*}$ since $x_{2 n}=f x_{2 n+1}$. For $x^{*}$ there exists $y^{\prime} \in X$ such that $x^{*}=g y^{\prime}$ and $x^{*} \sqsubseteq y^{\prime}$ by ii). By i),

$$
\begin{aligned}
d\left(x^{*}, y^{\prime}\right) & \leq A d\left(f x^{*}, g y^{\prime}\right)+B d\left(x^{*}, f x^{*}\right)+C d\left(y^{\prime}, g y^{\prime}\right)+D d\left(x^{*}, g y^{\prime}\right)+E d\left(f x^{*}, y^{\prime}\right) \\
& =[C+E] d\left(x^{*}, y^{\prime}\right) .
\end{aligned}
$$

So $x^{*}=y^{\prime}$ by (2) in Lemma 1, hence $f x^{*}=x^{*}=g y^{\prime}=g x^{*}$. Therefore $x^{*} \in \operatorname{Fix}(f) \cap \operatorname{Fix}(g)$. Similarly, we can give the same result for the case of $g$ being continuous.

If $x^{*}, y^{*} \in \operatorname{Fix}(f) \cap \operatorname{Fix}(g)$ then $x^{*}$ and $y^{*}$ are comparative, hence by i),

$$
\begin{aligned}
d\left(x^{*}, y^{*}\right) & \leq A d\left(f x^{*}, g y^{*}\right)+B d\left(x^{*}, f x^{*}\right)+C d\left(y^{*}, g y^{*}\right)+D d\left(x^{*}, g y^{*}\right)+E d\left(f x^{*}, y^{*}\right) \\
& \leq(A+D+E) d\left(x^{*}, y^{*}\right)
\end{aligned}
$$

so $x^{*}=y^{*}$ by (2) in Lemma 1. Hence $\operatorname{Fix}(f) \cap \operatorname{Fix}(g)=\left\{x^{*}\right\}$.

Modifying the idea of Zhang [16], we obtain next three corollaries.

Corollary 1 The conditions of $A, B, C, D, E$ in i) of Theorem 3 can be replaced by the following:

i') there exist $A, B, C, D, E \geq 0$ and $\epsilon>0$ such that $A+B+C+D+E=1+\epsilon, A+D+E<1, C+E<1$, $B+D<1, \quad(C-B)(D-E)>2 \epsilon$.

Proof Since $(C-B)(D-E)>2 \epsilon \Leftrightarrow A+C D+B E-\epsilon>A+\epsilon+B D+C E$ so

$$
A+C D+B E-\epsilon>A+\epsilon+B D+C E,
$$

hence $(1-B-C-D-E)+C D+B E>A(A+B+C+D+E)+B D+C E$ therefore

$$
K=\frac{A+B+E}{1-C-E} \frac{A+C+D}{1-B-D}<1 .
$$

Corollary 2 The conditions of $A, B, C, D, E$ in i) of Theorem 3 can be replaced by the following:

i") there exist $A, B, C, D, E \geq 0$ such that $A+B+C+D+E=1, C>B$ and $D>E$ or $C<B$ and $D<E$.

Proof Take $\epsilon>0$ such that $(C-B)(D-E)>2 \epsilon$ and $A+D+E+\epsilon<1$, and let $A^{\prime}=A+\epsilon$. Then the following holds: for all comparative elements $x, y \in X$,

$$
d(x, y) \leq A^{\prime} d(f x, g y)+B d(x, f x)+C d(y, g y)+D d(x, y)+E d(g x, y) .
$$

Obviously, $A^{\prime}, B, C, D, E$ satisfy i') in Corollary 1.

Corollary 3 The conditions of $A, B, C, D, E$ in 1 ) of Theorem 3 can be replaced by the following:

i"') there exist $A, B, C, D, E \geq 0$ such that $A+B+C+D+E<1$ and $B=C$ or $D=E$.

Proof Since $A, B, C, D, E<1$, so $A^{2}+A(1-A)<1-(B+C+D+E)$, hence

$$
A^{2}+A(B+C+D+E)+(C+E)(B+D)<1-(B+C+D+E)+(C+E)(B+D),
$$

or

$$
A^{2}+A(B+C+D+E)+(C+D)(B+E)<1-(B+C+D+E)+(C+D)(B+E),
$$

which implies that 


$$
\frac{A+C+E}{1-C-E} \frac{A+B+D}{1-B-D}<1
$$

or

$$
\frac{A+C+D}{1-C-D} \frac{A+B+E}{1-B-E}<1
$$

If $B=D$ or $D=E$, then the above two relations reduce

$$
K=\frac{A+B+E}{1-C-E} \frac{A+C+D}{1-B-D}<1 .
$$

The following is a non-continuous version of Theorem 3.

Theorem 4 Let $(X, \sqsubseteq, d)$ be a complete partially ordered-cone metric space. If $f, g: X \rightarrow X$ are maps such that i) and ii) in Theorem 3 hold and iii) or iv) holds

iii) if an increasing sequence $\left\{x_{n}\right\}$ converges to $x \in X$, then $x_{n} \sqsubseteq x$ and $x_{n} \sqsubseteq f x$ for all $n \in \mathbb{N}$ and $f^{2}=1_{X}$;

iv) if an increasing sequence $\left\{x_{n}\right\}$ converges to $x \in X$, then $x_{n} \sqsubseteq x$ and $x_{n} \sqsubseteq g x$ for all $n \in \mathbb{N}$ and $g^{2}=1_{X}$.

Then $f$ and $g$ have a common fixed point $x^{*} \in X$. Furthermore, if $x$ and $y$ in Fix $(f) \cap$ Fix $(g)$ are comparative and $A+D+E<1$, then $\operatorname{Fix}(f) \cap \operatorname{Fix}(g)$ is singleton.

Proof By i) and ii) in Theorem 3, we construct a sequence $\left\{x_{n}\right\}$ such that $x_{2 n}=f x_{2 n+1}, x_{2 n+1}=g x_{2 n+2}$, for all $n=0,1, \cdots$, and $x_{0} \sqsubseteq x_{1} \sqsubseteq x_{2} \sqsubseteq \cdots \sqsubseteq x_{n} \sqsubseteq \cdots$ and $x_{n} \rightarrow x^{*}$.

Case I: Suppose iv) holds, then $x_{n} \sqsubseteq x^{*}$ and $x_{n} \sqsubseteq g x^{*}$ for all $n \in \mathbb{N}$ and $g^{2}=1_{X}$. By i),

$$
\begin{aligned}
d\left(x^{*}, g x^{*}\right) \leq & d\left(x_{2 n+1}, x^{*}\right)+d\left(x_{2 n+1}, g x^{*}\right) \\
\leq & d\left(x_{2 n+1}, x^{*}\right)+A d\left(f x_{2 n+1}, g g x^{*}\right)+B d\left(x_{2 n+1}, f x_{2 n+1}\right) \\
& +C d\left(g x^{*}, g g x^{*}\right)+D d\left(x_{2 n+1}, g g x^{*}\right)+E d\left(f x_{2 n+1}, g x^{*}\right) \\
= & d\left(x_{2 n+1}, x^{*}\right)+A d\left(x_{2 n}, x^{*}\right)+B d\left(x_{2 n+1}, x_{2 n}\right) \\
& +C d\left(x^{*}, g x^{*}\right)+D d\left(x_{2 n+1}, x^{*}\right)+E d\left(x_{2 n}, g x^{*}\right) \\
\leq & \left(x_{2 n+1}, x^{*}\right)+A d\left(x_{2 n}, x^{*}\right)+B\left[d\left(x_{2 n+1}, x^{*}\right)+d\left(x^{*}, x_{2 n}\right)\right] \\
& +C d\left(x^{*}, g x^{*}\right)+D d\left(x_{2 n+1}, x^{*}\right)+E\left[d\left(x_{2 n}, x^{*}\right)+d\left(x^{*}, g x^{*}\right)\right],
\end{aligned}
$$

so we obtain

$$
d\left(x^{*}, g x^{*}\right) \leq L_{1} d\left(x_{2 n}, x^{*}\right)+L_{2} d\left(x_{2 n+1}, x^{*}\right),
$$

where $L_{1}=\frac{A+B+E}{1-C-E}$ and $L_{2}=\frac{1+B+D}{1-C-E}$ Since $x_{n} \rightarrow x^{*}$, for any $c \in \operatorname{Int} P_{0}$ there exist enough large $N \in \mathbb{N}$ such that $d\left(x_{2 n}, x^{*}\right) \ll \frac{c}{2 L_{1}}$ and $d\left(x_{2 n+1}, x^{*}\right) \ll \frac{c}{2 L_{2}}$ for all $n \geq N$, hence

$$
d\left(x^{*}, g x^{*}\right) \leq K_{1} d\left(x_{2 n}, x^{*}\right)+K_{2} d\left(x_{2 n+1}, x^{*}\right) \ll \frac{c}{2}+\frac{c}{2}=c, \forall n \geq N .
$$

So $d\left(x^{*}, g x^{*}\right)=0$ by (1) in Lemma 1 , hence $g x^{*}=x^{*}$.

For $x^{*} \in X$ there exists $y^{\prime} \in X$ such that $x^{*}=f y^{\prime}$ and $x^{*} \sqsubseteq y^{\prime}$ by ii). Hence by i),

$$
\begin{aligned}
d\left(y^{\prime}, x^{*}\right) & \leq A d\left(f y^{\prime}, g x^{*}\right)+B d\left(y^{\prime} f y^{\prime}\right)+C d\left(x^{*}, g x^{*}\right)+D d\left(y^{\prime}, g x^{*}\right)+E d\left(f y^{\prime}, x^{*}\right) \\
& =[B+D] d\left(y^{\prime}, x^{*}\right),
\end{aligned}
$$

so $y^{\prime}=x^{*}$ by (2) in Lemma 1. Hence $g x^{*}=x^{*}=f y^{\prime}=f x^{*}$, i.e., $x^{*} \in \operatorname{Fix}(f) \cap \operatorname{Fix}(g)$. 
Case II: Suppose iii) holds, then $x_{n} \sqsubseteq x^{*}$ and $x_{n} \sqsubseteq f x^{*}$ for all $n \in \mathbb{N}$ and $f^{2}=1_{X}$. By (1),

$$
\begin{aligned}
d\left(x^{*}, f x^{*}\right) \leq & d\left(x^{*}, x_{2 n+2}\right)+d\left(x_{2 n+2}, f x^{*}\right)=d\left(x^{*}, x_{2 n+2}\right)+d\left(f x^{*}, x_{2 n+2}\right) \\
\leq & d\left(x^{*}, x_{2 n+2}\right)+A d\left(f f x^{*}, g x_{2 n+2}\right)+B d\left(f x^{*}, f f x^{*}\right) \\
& +C d\left(x_{2 n+2}, g x_{2 n+2}\right)+D d\left(f x^{*}, g x_{2 n+2}\right)+E d\left(f f x^{*}, x_{2 n+2}\right) \\
= & d\left(x^{*}, x_{2 n+2}\right)+A d\left(x^{*}, x_{2 n+1}\right)+B d\left(f x^{*}, x^{*}\right) \\
& +C d\left(x_{2 n+2}, x_{2 n+1}\right)+D d\left(f x^{*}, x_{2 n+1}\right)+E d\left(x^{*}, x_{2 n+2}\right) \\
\leq & d\left(x^{*}, x_{2 n+2}\right)+A d\left(x^{*}, x_{2 n+1}\right)+B d\left(f x^{*}, x^{*}\right)+C\left[d\left(x_{2 n+2}, x^{*}\right)+d\left(x^{*}, x_{2 n+1}\right)\right] \\
& +D\left[d\left(f x^{*}, x^{*}\right)+d\left(x^{*}, x_{2 n+1}\right)\right]+E d\left(x^{*}, x_{2 n+2}\right),
\end{aligned}
$$

so we obtain

$$
d\left(x^{*}, f x^{*}\right) \leq L_{3} d\left(x_{2 n+1}, x^{*}\right)+L_{4} d\left(x_{2 n+2}, x^{*}\right),
$$

where $L_{3}=\frac{A+C+D}{1-B-D}$ and $L_{4}=\frac{1+C+E}{1-B-D}$ Since $x_{n} \rightarrow x^{*}$, for any $c \in \operatorname{Int} P_{0}$ there exist enough large $N \in \mathbb{N}$ such that $d\left(x_{2 n+1}, x^{*}\right) \ll \frac{c}{2 L_{3}}$ and $d\left(x_{2 n+2}, x^{*}\right) \ll \frac{c}{2 L_{4}}$ for all $n \geq N$, hence $d\left(x^{*}, f x^{*}\right) \leq L_{3} d\left(x_{2 n}, x^{*}\right)+L_{4} d\left(x_{2 n+1}, x^{*}\right) \ll \frac{c}{2}+\frac{c}{2}=c, \forall n \geq N$. So $d\left(x^{*}, f x^{*}\right)=0$ by (1) in Lemma 1 , that is, $f x^{*}=x^{*}$.

For $x^{*} \in X$ there exists $y^{\prime \prime} \in X$ such that $x^{*}=g y^{\prime \prime}$ and $x^{*} \sqsubseteq y^{\prime \prime}$ by ii). Hence by i),

$$
\begin{aligned}
d\left(x^{*}, y^{\prime \prime}\right) & \leq \operatorname{Ad}\left(f x^{*}, g y^{\prime \prime}\right)+B d\left(x^{*}, f x^{*}\right)+C d\left(y^{\prime \prime}, g y^{\prime \prime}\right)+D d\left(x^{*}, g y^{\prime \prime}\right)+E d\left(f x^{*}, y^{\prime \prime}\right) \\
& =[C+E] d\left(x^{*}, y^{\prime \prime}\right),
\end{aligned}
$$

so $y^{\prime \prime}=x^{*}$ by (1) in Lemma 1. Hence $f x^{*}=x^{*}=g y^{\prime \prime}=g x^{*}$, i.e., $x^{*} \in \operatorname{Fix}(f) \cap \operatorname{Fix}(g)$.

So in any case, $x^{*} \in \operatorname{Fix}(f) \cap \operatorname{Fix}(g)$ The uniqueness is obvious.

Remark 1 We can also modify Corollary 1 - 3 to give the corresponding corollaries of Theorem 4, but we omit the part.

Remark 2 In this paper, we discuss the common fixed point problems for mappings with quasi-contractive type (i.e., expansive type) on partially ordered cone metric spaces, but some authors in references discussed the same problems for contractive or Lipschitz type. So our results improve and generalize the corresponding conclusions.

\section{Acknowledgements}

This paper is supported by the NNSF of China (No. 11361063, No. 11361064).

\section{References}

[1] Huang, L. and Zhang, G.X. (2007) Cone Metric Spaces and Fixed Point Theorems of Contractive Mappings. Journal of Mathematical Analysis and Applications, 332, 1468-1476. http://dx.doi.org/10.1016/j.jmaa.2005.03.087

[2] Abbas, M. and Jungck, G. (2008) Common Fixed Point Results for Noncommuting Mappings without Continuity in Cone Metric Spaces. Journal of Mathematical Analysis and Applications, 341, 416-420. http://dx.doi.org/10.1016/j.jmaa.2007.09.070

[3] Abbas, M. and Rhoades, B.E. (2009) Fixed and Periodic Point Results in Cone Metric Spaces. Applied Mathematics Letters, 22, 511-515. http://dx.doi.org/10.1016/j.aml.2008.07.001

[4] Raja, P. and Vaezpour, S.M. (2008) Some Extensions of Banach’s Contraction Principle in Complete Cone Metric Spaces. Fixed Point Theory and Applications, 2008, Article ID: 768294. 
[5] Piao, Y.J. (2014) Unique Common Fixed Points for Mixed Type Expansion Mappings on Cone Metric Spaces. Acta Mathematica Sinica, Chinese Series, 57, 1041-1046.

[6] Jungck, G., Radenovic, S., Radojevic, S. and Rakočević, V. (2009) Common Fixed Point Theorems for Weakly Compatible Pairs on Cone Metric Spaces. Fixed Point Theory and Applications, 2009, Article ID: 643840.

[7] Ilić, D. and Rakočević, V. (2009) Quasi-Contraction on a Cone Metric Space. Applied Mathematics Letters, 22, 728731. http://dx.doi.org/10.1016/j.aml.2008.08.011

[8] Ran, A.C.M. and Reuring, M.C.B. (2004) A Fixed Point Theorem in Partially Ordered Sets and Some Application to Matrix Equations. Proceedings of the American Mathematical Society, 132, 1435-1443. http://dx.doi.org/10.1090/S0002-9939-03-07220-4

[9] Nieto, J.J. and Lopez, R.R. (2005) Contractive Mappings Theroem in Partially Ordered Sets and Applications to Ordinary Differential Equation. Order, 22, 223-239. http://dx.doi.org/10.1007/s11083-005-9018-5

[10] Agarwal, R.P., El-Gebeily, M.A. and O’Regan, D. (2008) Generalized Contractions in Partially Ordered Metric Spaces. Applicable Analysis: An International Journal, 87, 109-116. http://dx.doi.org/10.1080/00036810701556151

[11] Nieto, J.J. and Lopez, R.R. (2007) Existence and Uniqueness of Fixed Point in Partially Ordered Sets and Applications to Ordinary Differential Equations. Acta Mathematica Sinica, English Series, 23, 2205-2212. http://dx.doi.org/10.1007/s10114-005-0769-0

[12] Wang, C., Zhu, J.H., Damjanovic, B. and Hu, L.G. (2009) Approximating Fixed Points of a Pair of Contractive Mappings in Generalized Convex Metric Spaces. Applied Mathematics and Computation, 125, 1522-1525.

[13] Aitun, I., Damjanovic, B. and Djoric, D. (2010) Fixed Point and Common Fixed Point Theorems on Ordered Cone Metric Spaces. Applied Mathematics Letters, 23, 310-316. http://dx.doi.org/10.1016/j.aml.2009.09.016

[14] Jankovic, S., Kadelburg, Z., Radenovic, S. and Rhoades, B.E. (2009) Assad-Kirk-Type Fixed Point Theorems for a Pair of Nonself Mappings on Cone Metric Spaces. Fixed Point Theory and Applications, 2009, Article ID: 7610386.

[15] Azam, A., Beg, I. and Arshad, M. (2010) Fixed Point in Topological Space Valued Cone Metric Spaces. Fixed Point Theory and Applications, 2010, Article ID: 604084.

[16] Zhang, X. (2010) Common Fixed Point Theorem of Lipschitz Type Mappings on Con Metric Spaces. Acta Mathematica Sinica, Chinese Series, 53, 1139-1148. 
Scientific Research Publishing (SCIRP) is one of the largest Open Access journal publishers. It is currently publishing more than 200 open access, online, peer-reviewed journals covering a wide range of academic disciplines. SCIRP serves the worldwide academic communities and contributes to the progress and application of science with its publication.

Other selected journals from SCIRP are listed as below. Submit your manuscript to us via either submit@scirp.org or Online Submission Portal.
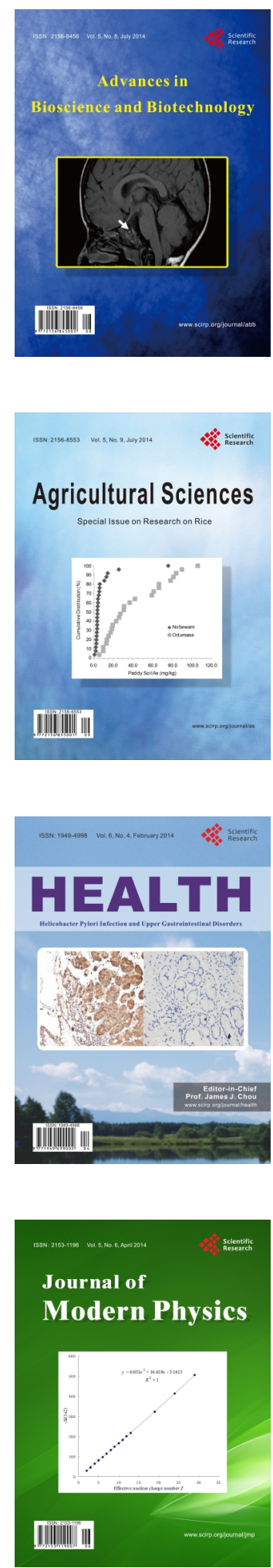
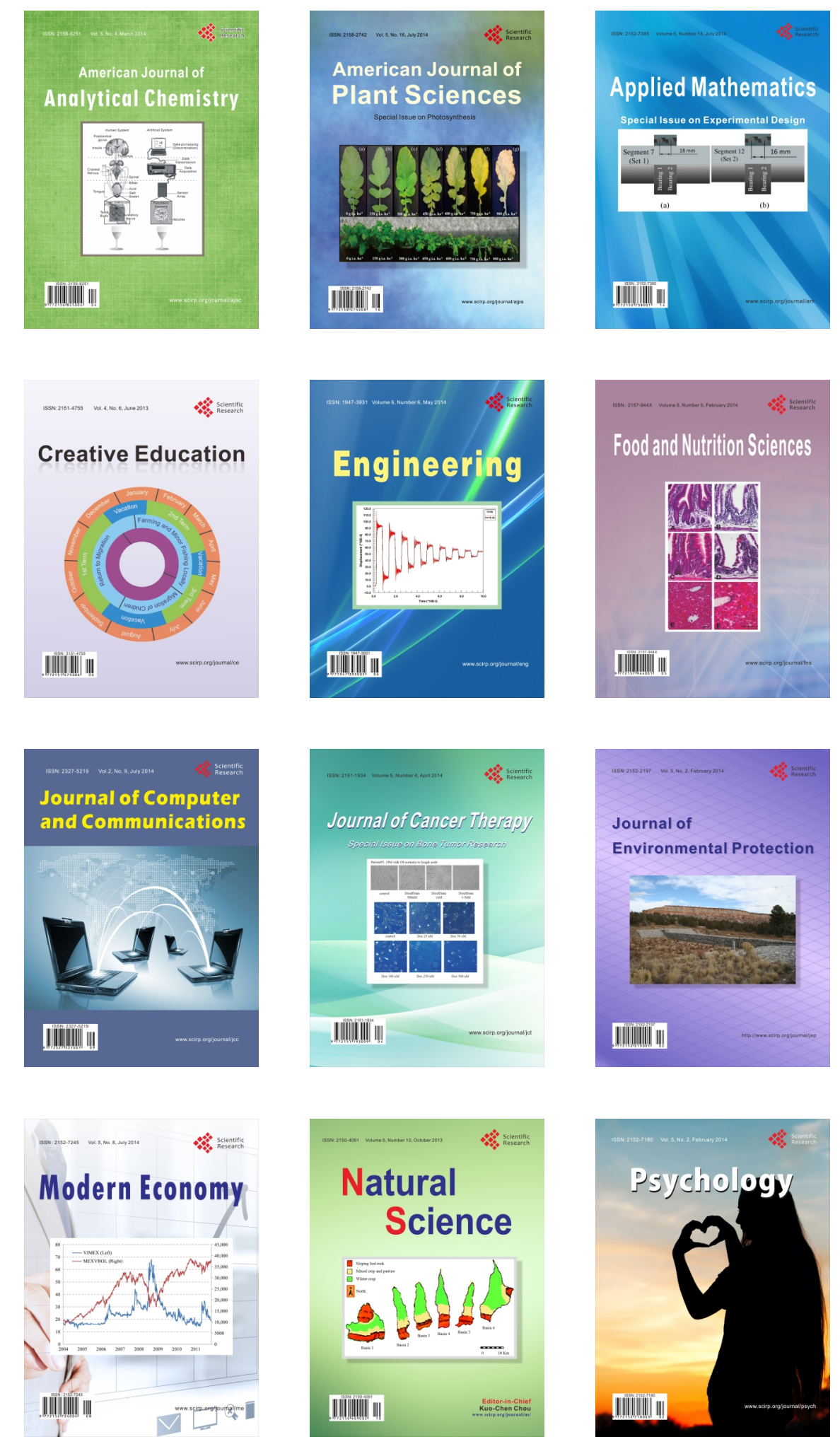